\title{
Psychological Predictors of Premarital Sexual Relationship among In-school Adolescents in a Western Nigerian City
}

\author{
Okeke, Sylvester Reuben ${ }^{1, *}$, Okeke-Obayemi ${ }^{2}$, Deborah Oluwatosin ${ }^{2}$ \\ ${ }^{1}$ Department of Human Kinetics and Health Education, University of Ibadan, Nigeria \\ ${ }^{2}$ Department of Guidance and Counselling, University of Ibadan, Nigeria
}

Copyright $\bigcirc 2016$ by authors, all rights reserved. Authors agree that this article remains permanently open access under the terms of the Creative Commons Attribution License 4.0 International License

\begin{abstract}
Adolescence is a stage in life that is considered very turbulent as the psychological and physiological changes that accompany this period predispose young people to risky sexual behaviour. Therefore, finding out factors that predict sexual behaviour among this group is an important issue for research. It is against this backdrop that this study was designed to investigate psychological predictors of premarital sexual relationships among in-school adolescents in a western Nigerian city. The descriptive survey research design was adopted in the study. A multi-stage sampling technique was used to select 675 respondents for the study although analysis was based on the 643 questionnaires that were returned from the field and found useful for analysis. Data was collected using a self-developed and modified instrument from standardized scales. The questionnaire was examined for reliability using the Cronbach alpha which yielded 0.81 coefficients. On the spot administration technique was used to collect data and the generated data were analysed using inferential statistics of regression models at 0.05 alpha level. The findings of the study showed that all the psychological variables investigated were found to significantly predict premarital sexual relationships among the respondents. Findings showed that self-esteem ( $R$ $=0.290$, Adj. $\left.\mathrm{R}^{2}=0.080, \mathrm{~F}_{(1,641)}=19.508, \mathrm{p}=0.000<0.05\right)$, self-efficacy $\left(\mathrm{R}=0.290\right.$, Adj. $\mathrm{R}^{2}=0.080, \mathrm{~F}_{(1,641)}=19.508, \mathrm{p}$ $=0.000<0.05)$, and attitude towards premarital sex $(\mathrm{R}=$ 0.290 , Adj. $\left.\mathrm{R}^{2}=0.080, \mathrm{~F}_{(1,641)}=19.508, \mathrm{p}=0.000<0.05\right)$ significantly predicted premarital sexual relationships among the respondents. It was therefore concluded that modifying psychological factors of self-esteem, self-efficacy and attitude towards premarital sex can be effective in regulating involvement in premarital sexual relationships among in-school adolescents in the city. Scaling up the level of school counseling especially in the area of sexual adjustment and modification of the psychological variables investigated were recommended.
\end{abstract}

Keywords Premarital Sexual Relationships,
Psychological Factors, In-school Adolescents

\section{Introduction}

Adolescence is a stage in life that is considered very turbulent as the psychological and physiological changes that accompany this period predispose young people to a number of risky behaviours. Adolescents are considered the most vulnerable group in terms of risk of sexually transmitted infections (STIs) because of their lifestyle which is predominantly marked by adventure seeking, experimentation and risk taking. The adolescent is caught in between the web of childhood and adulthood and as such, finds it difficult to operate either as a child or an adult. Efforts are made by the adolescents to prove to their parents and significant others which peers are prominent, that they are no longer kids. At this stage in life, they embark on many actions that have the potential of causing serious harm to their overall health and well-being.

As stated earlier, the period of adolescence has been largely described as a period of experimentation as adolescents try out almost everything. Sexual experimentation is a common area of experimentation among adolescents that is causing serious public health concern. According to the United Nation's Population Fund [1], adolescents and young adults are at the centre of HIV/AIDS as they account for the largest percentage of new infections. Various studies both in the developed world [2-4] and in the developing world [5-9] have reported that adolescents are not only sexually active but that sexual risk behaviour is also high.

High level of teenage pregnancies, abortions, school dropouts and sexually transmitted infections confirm that youths are engaged in early sexual activities that increasingly predispose them to HIV/AIDS. Apart from HIV/AIDS, there 
are other STIs that are as well as dangerous as HIV/AIDS. Findings of Ogundana [10] and Nigerian Demographic and Health Survey [11] reveal that there is a high level of awareness on HIV/AIDS and its preventive measures. However, findings of Ogundana [10], and Alikor as cited in Favieh [12] indicate that this knowledge is not reflected in sexual behaviours of young people. In another study, the researchers reported that a quarter of their respondents reveled that they often had unsafe sex with high risk partners.

In a survey of knowledge of HIV/AIDS and sexual behaviour among youths in South West Nigeria, Odu and Akanle [14] reported sexual activeness and risky sexual behaviours ranging from casual sex, same sex, multiple sex and transactional sex. In a related study by Okonkwo et al., [13] among student respondents in Anambra, $80.1 \%$ of the respondents revealed that their age mates were already sexually active, $92 \%$ indicated that their friends had regular sexual partners. On the issue of protective behaviour, only $58.5 \%$ of the respondents indicated use of condom among their sexually active friends and almost half of the respondents $(47.1 \%)$ indicated that they are under pressure by their peers to engage in premarital sex, similarly, Alikor in Fiaveh [12] reported a $61 \%$ prevalence rate of sexual intercourse with only $36.9 \%$ condom use among in-school young people surveyed in Port-Harcourt.

Young people are becoming increasingly exposed to the risk of HIV infection. According to the 2014-2015 HIV/AIDS Prevention Plan Report, 3.2 million Nigerians are living with HIV/AIDS with general population prevalence at $3.4 \%$ and $2.9 \%$ prevalence for adolescents aged between 15-19 years [15]. Primary prevention especially abstinence, remains one of the most realistic interventions for reducing further spread of the virus. However, the adoption of sexual abstinence as a prevention strategy among adolescents remains low and factors influencing its practice among urban young people in Nigeria are relatively unknown [16].

Globally, 36.9 million people were estimated to be living with HIV and 2 million were newly infected with HIV with 1.2 million AIDS related death as at the end of 2014 [17]. As the HIV epidemic spreads, younger age groups are becoming exposed to the risk of infection [1]. Ten million youth (ages 15-24) worldwide are living with HIV and every day, an estimated 6,000 youth are infected with the virus [18]. According to the Nigerian Federal Ministry of Health [19], the 2008 HIV/Syphilis Sentinel Survey in Nigeria revealed that $3.3 \%$ of young people aged $15-19$ are infected with the HIV virus. Sexual intercourse is the most predominant mode of transmission of HIV in sub-Saharan Africa, accounting for approximately $90 \%$ of all infections (Kock, Ekpririn \& Gnaore in Oladapo and Fayemi, [16]). Since adolescents are not homogenous and are affected by factors around them it is important to study factors predicting in-school adolescents' premarital sexual relationships. Although, perceptions about sexual abstinence and knowledge about HIV/AIDS prevention among in-school adolescents in Ibadan have been surveyed [16], this study is unique in that it aims at unraveling psychological factors that predict premarital sexual relationship among the population.

Various factors are suspected to predict premarital sexual relationship among young people and psychological factors of self-efficacy, self-esteem and attitude towards premarital sex are considered worth studying among the population. Attitude towards premarital sex is potent factor in premarital sexual relationships. Adolescents' attitude towards premarital sex, to a great extent determines their behaviour regarding sexuality vis-à-vis becoming sexually active or becoming abstinent. Park [20] revealed that attitude is not taught, rather it us caught. As such, various factors influence attitude formation and sexual attitude formation among adolescents in not exception. Attitude formation has been largely linked with social factors since man as a social animal is affected by everything around him. The family background one hails from, the kind of friends one keeps, the nature of movie one watches and the nature of book one reads go a long way in shaping his attitude.

Another important psychological factor that predicts premarital sexual relationships is self-efficacy. Self-efficacy has been defined as the individual's belief in their capability and capacity to carry out goal-directed behaviors within an activity context. It is how confident one feels about tackling certain tasks, challenges, and contexts [21-22]. Perceived self-efficacy, as put forth by Bandura in Chilisa, Tihabano, Vista, Pheko, Losike, Mosime, Mpeta, and Balogun [23] has been suggested to be a strong predictor of carrying out a recommended deed for instance abstinence and safer sex practices. In general, it is reported that persons who have confidence in their ability tend to view difficult tasks as meaningful challenges, even while others may deem similar tasks as discouraging. A lack of self-efficacy therefore may result in the individual having low aspirations, not trying harder and even giving up easily [24].

In the context of this study, self-efficacy, the perception that one can engage in protective behaviour has been highlighted as a key factor in predicting health-promoting behaviours [24]. One of such behaviours is condom self-efficacy, which is the individual's belief in their ability to use condoms effectively. Condom self-efficacy has been found to be a substantial predictor of engaging in safe sex behaviours. In addition, it was reported that after controlling for attitudes and perceptions of peer norms towards safer sex, condom self-efficacy predicted condom use [24]. In a separate study considering how well optimism about the future and self- esteem predict condom use efficacy, it was shown that self-efficacy is a multi-dimensional construct that comprise skills at condom use, social aspects of negotiating condom use with one's sexual partner as well as the ability to use condoms while under the influence of alcohol and drugs [25]. They considered communication to be among the factors of the self-efficacy model. Communication factors therefore speak to the capability of one to be assertive in their discussion with their sexual partner about the intent to use a condom and the capability to negotiate condom use even when faced with dissatisfaction or objection from the partner [25]. 
The above observation supported the relationship of self-efficacy to condom-use intention noted before in previous studies [26-28]. It thus seems apparent that one's belief in their ability to use condoms effectively may be an important factor to take into account in designing HIV prevention measures for adolescents [29]. Furthermore, self-efficacy has been identified as an important correlate of safe sex intentions and behaviour in their sample of Belgian adolescents in both native and ethnic minorities [28]. In their case, self-efficacy entailed the ability to suggest that a condom be used in a sexual relationship, the capability to employ a condom properly, and the confidence to use a condom. Also noteworthy is the findings made by Heeren, et. al., [27] study of the predictive value of the theory of planned behavior in a sample of university students in South Africa and the United States. The study identified self-efficacy among other variables as an important predictor of both condom use and intention to use condoms. Further, it has been shown that young people with greater motivational readiness and self-efficacy for safer sex were more likely to utilize condoms [30]. This in some way harmonized with earlier reports that self-efficacy mediated the relationship between motivational readiness to change and condom use [31]. In joining the quest to identify effective predictors of safe sex and total abstinence, Chilisa, et. al., [23] found that beyond condom efficacy, self-efficacy was impactful in the intention to limit sexual partners and intention to abstain from sex among Botswana students.

Moreover, self-esteem is another important psychological construct that predict premarital sexual relationship. Self-esteem connotes individuals' opinion of their selfworth or their ability to feel positive about themselves. It has also been identified as one of the factors that have the potential to influence health behaviours. Researchers have revealed a significant association between health behaviours and adolescents' self-esteem [32]. More recently, Geckil and Dundar [33] reported an important association between self-esteem and health risk behaviors of adolescents in their study. Specifically, they found that adolescents who scored low on self-esteem had higher scores for health risk behaviours. A key argument has been that low self-esteem places the individual at a high risk for taking part in risky behaviours such as risky sexual activities, including having unprotected sex and not limiting sexual partners [34]. Similarly, evidence abound that low self-esteem is strongly linked to unsafe sexual behavior among adult residents of a drug treatment programme [34]. Another study utilizing a large cross-sectional sample of South African adolescents observed that low self-esteem was linked to a number of risky behaviours including unprotected sex [35]. However an inverse relationship between high self-esteem and risky sexual behaviour has been reported [23]. It remains unclear whether high self-esteem is a good predictor of safe sex behaviours.

Since adolescents do not constitute a homogenous group but are affected by peculiarities and social dynamics in their environment, social research targeting different groups of adolescents in different location is needful to understand the peculiarities of each group and factors that predict their own sexual behaviour. It is against this backdrop that this study was designed to investigate psychological factors predicting premarital sexual relationships among in-school adolescents in Ibadan North Locality of Oyo State, Nigeria.

\section{Research Objectives}

The main objectives of this study are specifically to:

1. Examine the predictive effect of self-esteem on premarital sexual relationship

2. Examine the predictive effect of self-efficacy on premarital sexual relationship

3. Examine the predictive effect of attitude towards premarital sex on premarital sexual relationship

\section{Hypotheses}

The following hypotheses were tested for significance:

1. Self-esteem will not significantly predict premarital sexual relationship among in-school adolescents in Ibadan North LGA

2. Self-efficacy will not significantly predict premarital sexual relationship among in-school adolescents in Ibadan North LGA

3. Attitude towards premarital sex will not significantly predict premarital sexual relationship among in-school adolescents in Ibadan North LGA

4. The joint effect of psychological factors (self-efficacy, self-esteem and attitude towards premarital sex) will not significantly predict premarital sexual relationship among in- school adolescents in Ibadan North Local Government Area of Oyo State

\section{Methodology}

The descriptive survey research design was used in this study and the study population comprised in-school adolescents in Ibadan locality of Oyo State. A sample size of 675 in-adolescents was drawn from senior secondary schools in the locality using a multi stage sampling technique. The first stage involved purposive sampling technique to select public senior secondary schools in the local government area. At the second stage, simple random sampling technique was used to select 15 schools from the 30 public senior secondary schools in the local government area while purposive sampling technique was also be used to pick SS 1 and 2 as classes from the 15 selected schools. Respondents for the study were drawn from these classes using simple random sampling technique to pick 15 respondents, from 3 arms for each class to make 45 respondents from each school and 675 in all. 
The research instrument for this study was a questionnaire titled Psychologival Predictors of Premarital Sexual Relationship Questionnaire (PPPSRQ). The questionnaire has four scales reported in five sections viz:

Section A: This scale is concerned with demographic information of the respondents. There are four items in this section.

Section B: This is titled Attitude towards Premarital Sex Scale. It is self-designed to seek information on the attitude of respondents towards premarital sex. It contains a total of ten items on the modified Likert format scale.

Section C: This is titled Self-Esteem Scale. It is designed to seek information on the self-esteem level of the respondents. It has a total of ten items on the modified Likert format scale and was modified from Rosenberger's General Self Esteem Scale.

Section D: This is titled Self-Efficacy Scale and it was modified from the General Self Efficacy Scale developed by Schwarzer and Jerusalem (1995). The scale was originally created to assess a general sense of perceived self-efficacy with the aim in mind to predict coping with daily hassles as well as adaptation after experiencing all kinds of stressful life events and can be modified to suit any particular area of interest. The scale is designed for the general adult population, including adolescents and young adults. The modified scale for this study is designed along a four point modified Likert scale.

Section E: This is titled Premarital Sexual Relationship Scale and it was self-developed to assess premarital sexual relationship among the respondents. The scale has a total of twelve items on the modified Likert Format Scale.

The research instrument was subjected to experts judgment for content and construct validity. Suggestions from the experts were used to improve the quality of the questionnaire. The questionnaire forms were thereafter administered to 30 in-school adolescents in another locality in the state. Cronbach alpha reliability statistics was used to test the internal consistency of the questionnaire which stood at 0.81 . The field survey was conducted by the principal investigators with the approval of the school authority. The completed copies of the questionnaire were collected from the respondents on the spot. The essence of using on the spot administration technique was to minimize loss of questions and ensure high level of return. The completed copies of the questionnaire were collated and analysed using SPSS package. Inferential statistics regressions models at 0.05 level of significant was used to test the hypotheses.

\section{Result}

\section{Hypothesis One}

Self-esteem will not significantly predict premarital sexual relationship among in-school adolescents in Ibadan North locality of Oyo State.
Table 1. Predictive Effect of Self Esteem on Premarital Sexual relationship

\begin{tabular}{|c|c|c|c|c|c|}
\hline R & \multicolumn{5}{|c|}{0.087} \\
\hline R Square & \multicolumn{5}{|c|}{0.008} \\
\hline \multicolumn{5}{|c|}{ ANOVA } \\
\hline \multicolumn{2}{|c|}{$\begin{array}{c}\text { Sum of } \\
\text { square }\end{array}$} & Df & Mean square & F & Sig. \\
\hline Regression & 556.461 & 1 & 556.461 & $\begin{array}{c}4.85 \\
4\end{array}$ & 0.000 \\
\hline Residual & 73481.707 & 641 & 114.636 & & \\
\hline Total & 74038.168 & 642 & & & \\
\hline
\end{tabular}

a Predictors: (Constant) (SELF ESTEEM)

b Dependent Variable: (PREMARITAL SEXUAL RELATIONSHIP)

The finding of the study as shown in the table indicates that self-esteem is a significant predictor of premarital sexual relationship among respondents $(R=0.087, p=0.000<0.05)$. The findings of the study further revealed that $0.6 \%$ (Adj. $\mathrm{R}^{2}$ $=0.006)$ of the variance in premarital sexual relationship among the respondents were accounted for by self-esteem. The results from the regression analysis shows that there was significant predictive effect of self-esteem on premarital sexual relationship; $\mathrm{F}(1,641)=4.854, \mathrm{p}=0.000<0.05$. Based on this, the null hypothesis is rejected and the alternate hypothesis upheld.

\section{Hypothesis Two}

Self-efficacy will not significantly predict premarital sexual relationship among in-school adolescents in Ibadan North Local Government Area of Oyo State

Table 2. Predictive Effect of Self Efficacy on Premarital Sexual relationship

\begin{tabular}{|c|c|c|c|c|c|}
\hline \multicolumn{2}{|c|}{$\mathrm{R}$} & \multicolumn{4}{|c|}{0.192} \\
\hline \multicolumn{2}{|c|}{ R Square } & \multicolumn{4}{|c|}{0.037} \\
\hline \multicolumn{2}{|c|}{ Adjusted R Square } & \multicolumn{4}{|c|}{0.035} \\
\hline \multicolumn{6}{|c|}{ ANOVA } \\
\hline & $\begin{array}{l}\text { Sum of } \\
\text { square }\end{array}$ & df & $\begin{array}{l}\text { Mean } \\
\text { square }\end{array}$ & $\mathrm{F}$ & Sig. \\
\hline Regression & 2738.749 & 1 & 556.461 & 24.622 & 0.000 \\
\hline Residual & 71299.419 & 641 & 114.636 & & \\
\hline Total & 74038.168 & 642 & & & \\
\hline
\end{tabular}

a Predictors: (Constant) (SELF EFFICACY)

b Dependent Variable: (PREMARITAL SEXUAL RELATIONSHIP)

The finding of the study as shown in the table indicates that self-efficacy is a significant predictor of premarital sexual relationship among the respondents $(R=0.192$, $\mathrm{p}=0.000<0.05$ ). The findings of the study further revealed that $3.5 \%$ (Adj. $\mathrm{R}^{2}=0.035$ ) of the variance in premarital sexual relationship among the respondents were accounted for by self-efficacy. The results from the regression analysis shows that there was significant predictive effect of self-efficacy on premarital sexual relationship; $F(1,641)=$ 24.622, $\mathrm{p}=0.000<0.05$. Therefore the null hypothesis is rejected. 


\section{Hypothesis Three}

Attitude toward premarital sex will not significantly predict premarital sexual relationship among in-school adolescents in Ibadan North Local Government Area of Oyo State

Table 3. Predictive Effect of Attitude towards Premarital sex on premarital sexual relationship

\begin{tabular}{|c|c|c|c|c|c|}
\hline \multicolumn{2}{|c|}{$\mathrm{R}$} & \multicolumn{4}{|c|}{0.154} \\
\hline \multicolumn{2}{|c|}{ R Square } & \multicolumn{4}{|c|}{0.024} \\
\hline \multicolumn{2}{|c|}{ Adjusted R Square } & \multicolumn{4}{|c|}{0.022} \\
\hline \multicolumn{6}{|c|}{ ANOVA } \\
\hline & $\begin{array}{l}\text { Sum of } \\
\text { square }\end{array}$ & $\mathrm{DF}$ & $\begin{array}{c}\text { Mean } \\
\text { square }\end{array}$ & $\mathrm{F}$ & Sig. \\
\hline Regression & 1745.197 & 1 & 1745.197 & $\begin{array}{c}15.47 \\
4\end{array}$ & 0.000 \\
\hline Residual & 72292.971 & 641 & 112.782 & & \\
\hline Total & 74038.168 & 642 & & & \\
\hline
\end{tabular}

a. Predictors: (Constant) (ATTITUDE TOWARDS SEX)

b. Dependent Variable: (PREMARITAL SEXUAL RELATIONSHIP)

The finding of the study as shown in the table indicates that attitude towards premarital sex significantly predicted premarital sexual relationship among the respondents $(\mathrm{R}=$ $154, \mathrm{p}=0.000<0.05)$. The findings of the study also revealed that $2.2 \%$ (Adj. $\mathrm{R}^{2}=0.022$ ) of variance in premarital sexual relationship among the respondents were accounted for their attitude towards premarital sex. The results from the regression analysis shows that there was significant predictive effect of attitude towards premarital sex on premarital sexual relationship; $F(1,641)=4.15 .474$, $\mathrm{p}=0.000<0.05$. Consequently, the null hypothesis is rejected and the hypothesis upheld.

\section{Hypothesis Four}

The joint effect of psychological factors (self-efficacy, self-esteem and attitude towards premarital sex) will not significantly predict premarital sexual relationship among in- school adolescents in Ibadan North Local Government Area of Oyo State

Table 4. Predictive Effect of Psychological Factors (self-efficacy, self-esteem and attitude towards premarital sex) on Premarital Sexual Relationship

\begin{tabular}{|c|c|c|c|c|c|}
\hline \multicolumn{2}{|c|}{$\mathrm{R}$} & \multicolumn{4}{|c|}{0.290} \\
\hline \multicolumn{2}{|c|}{ R Square } & \multicolumn{4}{|c|}{0.084} \\
\hline \multicolumn{2}{|c|}{ Adjusted R Square } & \multicolumn{4}{|c|}{0.080} \\
\hline \multicolumn{6}{|c|}{ ANOVA } \\
\hline & $\begin{array}{c}\text { Sum of } \\
\text { square }\end{array}$ & $\mathrm{DF}$ & $\begin{array}{c}\text { Mean } \\
\text { square }\end{array}$ & $\mathrm{F}$ & Sig. \\
\hline $\begin{array}{c}\text { Regressio } \\
n\end{array}$ & 6212.005 & 3 & 2070.668 & $\begin{array}{c}19.50 \\
8\end{array}$ & 0.000 \\
\hline Residual & 67826.163 & 639 & 106.144 & & \\
\hline Total & 74038.168 & 642 & & & \\
\hline
\end{tabular}

a Predictors: (Constant) (THE JOINT EFFECT OF PSYCHOLOGICAL FACTORS: SELF-EFFICACY, SELF-ESTEEM AND ATTITUDE TOWARDS PREMARITAL SEX)

b Dependent Variable: (PREMARITAL SEXUAL RELATIONSHIP)
The finding of the study as shown in the table above indicates that the joint effect of psychological factors (self-efficacy, self-esteem and attitude towards premarital sex) is a significant predictor of premarital sexual relationship among the respondents $(\mathrm{R}=0.290$, $\mathrm{p}=0.000<0.05$ ). The findings of the study further revealed that $8.0 \%$ (Adj. $\mathrm{R}^{2}=0.080$ ) of the variance in premarital sexual relationship among the respondents were accounted for by the joint effect of psychological factors (self-efficacy, self-esteem and attitude towards premarital sex). The results from the regression analysis show that the joint effect of psychological factors (self-efficacy, self-esteem and attitude towards premarital sex) significantly predicted premarital sexual relationship; F $(3,639) 19.508, \mathrm{p}=0.000<0.05$. This leads to the rejection of the null hypothesis.

\section{Discussion}

Self-efficacy defines an individual's belief in his/her capability and capacity to carry out goal-directed behaviors within an activity context. It is how confident one feels about tackling certain tasks, challenges, and contexts. In the case of this study, abstinence is as good as impossible among young people because influence that ranges from social, psychological and socio-economic. The confidence an adolescent has of his/her ability to maintain chastity plays a great role in determining premarital sexual relationship of the adolescent. Adolescents with low self-efficacy have been found to be more sexually active compared to those with higher self-efficacy. The finding of the study that indicates the self-efficacy is a significant predictor of premarital sexual relationship is in line with the findings of previous studies. It corroborates the findings of Tsai et al., [24] and the findings of Chilisa et al., [23] which also found significant relationship between self- efficacy and premarital sexual behaviour among young people.

The findings of the study equally showed that self-esteem is also a significant predictor of premarital sexual relationship among the respondent. Self-esteem is another psychological construct that has significant influence on health behaviour including sexual behaviour. The worth an individual has on oneself will greatly determine how such an individual will react to external and internal pressures to engage in premarital sexual relationships. Young people with low self-esteem are not only involved in premarital sexual activity but also risky sexual behaviour. This is because the poor worth they place on themselves drastically reduces their ability to fend off a sexual advance. It is very important that parents, teachers and counselors as well as other caregiver ensures that adolescents are enabled to develop a high sense of self-worth. Occasions by which parents and/or teachers engage in acts that denigrate the self-worth of adolescents especially adolescent girls make them vulnerable to permissive lifestyle as they would do anything to please anyone that considers and treats them in a special way. The findings of the study that found self-esteem 
as a significant predictor of premarital sexual relationship confirm the findings of Geckil and Dundar [33] which showed similar result in their study involving adolescents and young people.

Attitude, they say is everything and the place of attitude in predicting health behaviour is enormous. The attitude adolescents have towards premarital sex can largely shape their premarital sexual relationship behaviour. Adolescents who see nothing wrong in engaging in premarital sex or who can find watery justification to engage in premarital sex are more likely to initiate and maintain romantic relationships compared to adolescents who see premarital sex as wrong. The findings of the study which show attitude towards premarital sex is a significant predictor of premarital sexual relationship that among the respondents therefore is in line with the earlier finding of Blink-Pike et al., [36] who reported that boys and girls who initiate sexual intercourse in early adolescence are more likely than abstinent adolescents to approve of sex among unmarried teenagers. It is also in line with the finding of Kirby [37] who concluded from his study that changing adolescents' attitudes toward sex may be one of the most effective ways to reduce youth involvement in risky sexual behaviors and help prevent teenage pregnancy as studies have consistently found a strong link between adolescents' attitudes toward sex and their later sexual behaviours.

\section{Conclusion and Recommendations}

The findings of the study showed that self-esteem, self-efficacy and attitude towards premarital sexual relationships are modifiable factors influencing involvement in premarital sexual relationship among in-school adolescents in Ibadan North locality. Based on this conclusion, the following recommendations were made:

1. There is an urgent need of designing an intervention on addressing the high level of premarital sexual relationships among in-school adolescents in the study area

2. There is equally need for educational and therapeutic measures to help adolescents with low self-esteem as well as those with low self-efficacy since the findings of the study revealed that both constructs were significant predictors of premarital sexual relationship among the respondents

3. Intervention aimed at addressing poor attitude towards premarital sex as is the case in the developed world must be given serious consideration in this clime to help stem the tide of risky sexual behaviour among young people and their ugly concomitants.

4. There is need to employ more counselors in school and equip this counselors with all they need to ensure that sexual maladjustment among students in school is prevented and corrected

5. Teachers and parents alike must wake up to their responsibilities of playing monitoring and supervisory roles on their students and children respectively. This is very important to reduce negative peer influences which the study showed could predispose young people to premarital sexual relationships in school.

\section{Conflict of Interest}

No conflict of interest.

\section{REFERENCES}

[1] United Nations Population Fund (2007) Preventing HIV Infection: Young People. Population Issues.

[2] Somers, C.L \& Ali, W.F (2011) The Role of Parents in Early Adolescent Sexual Risk- Taking Behavior. The Open Psychology Journal, 4, 88-95

[3] Maguen, S. \& Annistead, L. (2006) Abstinence among Female Adolescents: Do Parents Matter Above and Beyond the Influence of Peers? American Journal of Orthopsychiatry, 76(2): 260-64.

[4] Caminis, A., Henrich, C., Ruchkin, V., Schwab-Stone, M., \& Martin, A. (2007). Psychosocial Predictors of Sexual Initiation and High-Risk Sexual Behaviors in Early Adolescence. Child and Adolescent Psychiatry and Mental Health, 1:14

[5] Fatusi, A.O \& Blum, R.W (2008): Predictors of Early Sexual Initiation among a Nationally Representative Sample of Nigerian Adolescents. BMC Public Health, 8:136 doi:10.1186/1471-2458-8-136

[6] Anyanwu, F.C \& Okeke, S.R. (2012). HIV/AIDS and Youths' Risky Sexual Behaviour: A Challenge to the Realization of Vision 20:2020. Journal of the Nigerian Association for Physical, Health Education, Recreation, Sports and Dance, 3 (2): 1-14.

[7] Ajuwon, A.J. (2013). Adolescence: The excitement, complexities and challenges. An Inaugural Lecture Delivered at the University of Ibadan, Ibadan on June 27, 2013.

[8] Anyanwu, F.C \& Okeke, S.R. (2015). Influence of Alcohol Abuse on Risky Sexual Behaviour of Tertiary Institution Students Attending Night Clubs in Ibadan. Nigerian Journal of Health Education 18(1): 96-109

[9] Okeke, S.R. (2016). University Spatial and Social Setting as Predictor of Risky Sexual Behaviour: Implications for School Health and Safety. Journal of Modern Education Review,(Forth-Coming).

[10] Ogundana, F (2002) Attitude to Death on Obstacle to Sexual Behavioural Change among Men in Urban Ekiti. Nigerian Journal of Counselling and Applied Psychology, 1(1):56-57

[11] National Planning Commission National Demographic and Health Survey 2008. Abuja Nigeria. The Commission, 2009.

[12] Fiaveh, D.Y (2011) Male Perspective(s) on Condom Use: Context of STI/HIV Prevention in the University of Ghana 
Community. Journal of Public Health and Epidemiology 3(1): 17-27.

[13] Okonkwo, P.I, Fatusi. A.O \& Ilika, A.L (2005) Perception of Peers' Behaviour Regarding sexual Health Decision Making among Female Undergraduates in Anambra State, Nigeria. African Health Sciences, 5(2):107-113

[14] Odu, B.K \& Akanle, F.F (2008) Knowledge of HIV/AIDS and Sexual Behaviour among the Youths in South West Nigeria. Humanity and Social Sciences Journal 3(1): 81-88.

[15] National Agency for the Control of AIDS (2014). National HIV/AIDS Prevention Plan 2014-2015. http://sbccvch.naca.gov.ng/sites/default/files/National\%20HI V\%20PrevPlan\%202014-2015(1).pdf

[16] Oladepo, O \& Fayemi, M (2011): Perceptions about Sexual Abstinence and Knowledge of HIV/AIDS Prevention among In-School Adolescents in a Western Nigerian city. $B M C$ Public Health, 11:304doi:10.1186/1471-2458-11-304

[17] UNAIDS (2015). AIDS Global Statistics Report. http://www.unaids.org/en/resources/campaigns/HowAIDSch angedeverything/factsheet

[18] Federal Ministry of Health, Nigeria (2008): National HIV/Syphilis Seroprevalence Sentinel Survey, Process and Findings National AIDS/STDs Control Programme (NASCP). Abuja, Nigeria.

[19] United Nations Population Fund, (UNFPA) (2005): State of World Population (2005). The Promise of Equality: Gender Equity, Reproductive Health and the Millennium Development Goals. Technical Report United Nations Population Fund, New York. http://www.unfpa.org/public/ca che/offonce/publications/pidJ1343]

[20] Park, K. (2015) Preventive and Social Medicine. (23 ${ }^{\text {rd }}$ Ed). Jabalpur: Bhanot Publishers.

[21] Hughes, A., Gaibraith, D. \& White, D. 2011. Perceived Competence: A Common Core for Self-Efficacy and Self-Concept? Journal of Personality Assessment, 93(3): 278289.

[22] Goetz, T., Cronjaeger, H., Frenzel, A.C, Ludtke, O. \& Hall, N.C. (2010). Academic Self- Concept and Emotion Reflections: Domain Specificity \& Age Effects. Contemporary Education Psychology 35(1): 44-58

[23] Chilisa, R., Tihabano, K., Vista, C., Pheko, M., Losike, N., Mosime, S., Mpeta, K., \& Balogun, S.K. 2013. Self-efficacy, Self-esteem and the Intention to Practice Safe Sex among Botswana Adolescents. IOSR Journal of Humanities and Social Science. 9(2): 87-95

[24] Tsai, C., Chuang, S., Liang, J., \& Tsai, M. (2011). Self-Efficacy in Internet-Based Learning Environments: A literature review. Journal of Educational Technology \& Society, 14(4): 222-240
[25] Bryan, A., Aiken, L.S., \& West, S.G. (2004). HIV/STD Risk among Incarcerated Adolescents: Optimism about the Future and Self Esteem as Predictors of Condom Use Self-Efficacy. Journal of Applied Social Psychology; 34: 912-936.

[26] Buhi, E.R. \& Goodson, P. (2007). Predictors of Adolescent Sexual Behaviour and Intention. Journal of Adolescent Behavior, 40(7): 4-12.

[27] Heeren, G., Jemmott III, J. B., Mandeya, A., \& Tyler, J. C. (2007). Theory-based Predictors of Condom Use among University Students in the United States and South Africa. AIDS Education \& Prevention 19(1): 1-12.

[28] Hendrickx, K., Philips, H., \& Avonts, D. (2008). Correlates of Safe Sex Behaviour among Low-Educated Adolescents of Different Ethnic Origin in Antwerp, Belgium. The European Journal of Contraception and Reproductive Health Care, 13(2), 164-172.

[29] Lescano, C. M., Celia, L. K., Miller, P. M., \& Puster, K. L. (2007). Unsafe Sex: Do Feelings Matter? Journal of Prevention \& Intervention in the Community, 33(1/2), 51-62.

[30] Outlaw, A., Naar-King, S., Janisse, H., \& Parsons, J. T. (2010). Predictors of Condom Use in a Multisite Study of High-Risk youth Living with HIV. AIDS Education and Prevention, 22(1):1-14

[31] Naar-king, S., Wright, K., Parsons, J., Frey, M., Templin, T., Lamp, P., \& Murphy, D. (2006). Healthy choices: Motivational Enhancement Therapy for Health Risk Behaviors in HIV+ Youth. AIDS Education and Prevention, $18,1-11$.

[32] Neumark-sztainer, D., Paxton, S.J., Hanna, P. J., Hanes, J. \& Story, M. (2006). Does Body Satisfaction Matter? Five Year Longitudinal Association between Body Satisfaction and Health Behaviors in Adolescent Females and Males. Journal of Adolescent Health 39(2): 244-251

[33] Geckil, E. \& Dundar, O. (2011). Turkish Adolescent Health Risk Behaviours and Self- Esteem. Social Behaviour and Personality. 39(2): 219-227

[34] Lejuez, C. W., Simmons, B. L., Aklin, W.M., \& Daughters, S. B. (2004). Risk-Taking Propensity and Risky Sexual Behaviour of Individuals in Residential Substance Use of Individuals in Residential Substance Use Treatment. Addictive Behaviors, 29(8): 1643-1647.

[35] Wild, L.G, Bhana, A. \& Lombard, C. (2004). Substance Abuse, Suicidality and Self- Esteem in South African Adolescents. Journal of Drug Education, 34(1): 1-17

[36] Blink-Pike, L., Berger, T., Hewett, J. \& Oleson, J. (2004). Sexually Abstinent Adolescents: An 18-Month Follow-Up. Journal of Adolescent Research, 19(5): 495-511.

[37] Kirby, D. (2007). Emerging Answers 2007: Research Findings on Programs to Reduce Teen Pregnancy and Sexually Transmitted Diseases. Washington, DC: National Campaign to Prevent Teen Pregnancy. 